higher risk grading than the predominantly expert-opinion based SOC. Construct validation of the ERIKO-Score is ongoing.

References:

[1] Dougados M, et al. Ann Rheum Dis 2014;73:62-8

[2] Dougados M, et al. Ann Rheum Dis 2015;74:1725-33.

Acknowledgements: We are grateful to Dr. Imma Fischer (Tübingen) for statistical support.

Disclosure of Interest: K. Krüger Consultant for: AbbVie Deutschland $\mathrm{GmbH}$ \& Co. KG, Speakers bureau: AbbVie Deutschland GmbH \& Co. KG, R. Eder Consultant for: AbbVie Deutschland $\mathrm{GmbH}$ \& Co. KG, C. Müller Shareholder of: Abbvie Inc., Employee of: AbbVie Deutschland GmbH \& Co. KG, R. Hecker Shareholder of: Abbvie Inc., Employee of: AbbVie Deutschland GmbH \& Co. KG DOI: 10.1136/annrheumdis-2017-eular.3395

\section{THU0151 ACPA ARE ASSOCIATED WITH LOW BONE MINERAL DENSITY IN RHEUMATOID ARTHRITIS}

L. Bautista Aguilar, A. Salmoral Chamizo, R. Jimenez Gasco, I. Gomez Gracia, P. Font Ugalde, M.L. Ladehesa Pineda, E.C. Lopez Medina, L. Perez Sanchez, A. Escudero Contreras, E. Collantes Estevez. Rheumatology, Reina Sofia University Hospital/IMIBIC/ University of Cordoba, Cordoba, Spain

Background: Several studies have related ACPA with the presence of bone erosion in rheumatoid arthtitis patients as they induce the differentiation and activation of osteoclasts

Objectives: Our main aim is to evaluate the association of ACPA with bone mineral density (BMD) in RA

Methods: Case-control study of 73 RA patients (2010 EULAR criteria) and a long standing disease of 5 years. Demographic and clinical variables were collected. BMD values using densitometry at the lumbar $(\mathrm{CL})$, hip $(\mathrm{CT})$ and femoral neck (CF) were collected. The presence of low bone mineral density (osteopenia: tscore $\leq-1$ ) and ACPA levels were compared using logistic regression analysis, adjusting variables related to BMD: age, sex, menopause, body mass index (BMI), habit Smoking, disease duration, daily corticoid doses, methotrexate treatment and inflammatory disease activity (DAS28)

Results: A group of 73 patients were included (14 men) with a mean age of $66,45 \pm 10,41$ years, mean body mass index $28,48 \pm 5,22 \mathrm{~kg} / \mathrm{m}^{2}$, mean long standing disease of $2,28 \pm 1,75$ years and mean DAS 28 of $3,17 \pm 1,18$. A total of 29 patients were negative for ACPA compared to 44 patients that were positive for ACPA. Osteopenia in lumbar spine was found in $82.2 \%$ of patients $65.8 \%$ hip and $75.3 \%$ in femoral neck. Logistic regression was performed without finding statistically significant association between osteopenia and inflammatory activity (DAS 28), vitamin D levels and positive rheumatoid factor, adjusted for variables that can modify BMD. ACPA Positive (any titer) were associated with the presence of lumbar spine osteopenia (OR 7.19, 95\% Cl 1.77-29.17) $(p=0.006)$, hip (OR 15.17, 95\% Cl 3.96-58.18) $(\mathrm{p}=0.001)$ and femoral neck (OR 3.76; 95\% Cl 1.20-11.82) ( $\mathrm{p}=0.023)$. In addition, a simple variance analysis (ANOVA) was performed to compare T scores and ACPA levels divided into three categories: $\leq 25 \mathrm{U} / \mathrm{mL}, 25-300 \mathrm{U} / \mathrm{mL}$ and $>300 \mathrm{U} / \mathrm{mL}$. ACPA group $\leq 25 \mathrm{U} / \mathrm{mL}$ differed in mean $T$ score values in lumbar spine, hip and femoral neck. No differences were found between ACPA positive patients with low and high levels for $\mathrm{T}$ score values. Conclusions: ACPA positivity in RA is associated with an increased risk of osteopenia in lumbar spine, hip and femoral neck independently of other variables that may modify bone mineral density. These data suggest that ACPA may play a role in bone remodeling

References:

[1] Referencias: Harre et al.J Clin Invest (2012), 122(5):1791-1802.

[2] Bugatti et al. Arthritis Research \& Therapy (2016), 18:226.

[3] Geusens and Lem. Arthritis Research \& Therapy (2011), 13:242.

Disclosure of Interest: None declared

DOI: 10.1136/annrheumdis-2017-eular.4422

\section{THU0152 WHO ARE THE PATIENTS WITH RHEUMATOID ARTHRITIS (RA) WHO ARE GETTING COMORBIDITY SCREENING PROCEDURES IN ACCORDANCE WITH GUIDELINES? A STUDY OF 769 ESTABLISHED RA PATIENTS}

L. Gossec, F. Foissac, M. Soubrier, F. Fayet, T. Bardin, C. Beauvais, G. Chales, I. Chary-Valckenaere, E. Dernis, L. Euller-Ziegler, R.-M. Flipo, P. Gaudin, S. Guis, T. Marhadour, X. Mariette, G. Mouterde, S. Pouplin, P. Richette, A. Ruyssen-Witrand, T. Schaeverbeke, J. Sibilia, M. Dougados. COMEDRA working group, Paris, France

Background: Patients with RA are either more at risk of, or less well screened for, several comorbidities including cardiovascular (CV) risk, cancer, infections and osteoporosis.[1] Recommendations have been developed on how and at what frequency to screen for comorbidities in RA patients.[2]

Objectives: to characterise patients who are being screened correctly (i.e., in accordance with recommendations).

Methods: Study design: This was an open long-term (3 years) extension of the COMEDRA 6 month randomized controlled trial in which patients with definite, stable RA were visiting a nurse for comorbidity assessment and screening counselling.[3] For this analysis, only the final visit data were used cross- sectionally. Assessment of comorbidity screening: A score was developed to quantify comorbidity screening procedures in accordance with guidelines:[4] this score gives 50 points to $\mathrm{CV}$ risk screening, 20 points to cancer screening, 20 points to pneumococcus and influenza vaccination and 10 points to osteoporosis screening. The score ranges $0-100$ and 0 indicates optimal screening. Factors associated with optimal screening: demographic and disease characteristics were compared between patients considered well-screened (lowest tertile for screening score) versus other patients. Statistical analysis: Variables with $p<0.20$ in univariate analysis were entered into the multivariate analysis using a backward stepwise logistic regression.

Results: 769 patients were assessed: mean $( \pm S D)$ age $62( \pm 11)$ years, mean disease duration $17( \pm 10)$ years; $614(80 \%)$ were women and $535(70 \%)$ were receiving a biologic. Disease was well-controlled (mean DAS28 $2.8 \pm 1.3$ ). The mean comorbidity screening score was $24.3( \pm 17.8)$ (range, $0-100)$. The 316 patients $(41 \%$ of all patients) in the lowest tertile for this score (i.e., with a score $\leq 15)$ were less often smokers: odds ratio [95\% confidence interval] 0.45 [0.28 0.72 ], were more often treated for hyperlipidemia (2.58 [1.85-3.61]), and were more often treated with a biologic $(1.97$ [1.4 - 2.76]).

Conclusions: Comorbidity screening is suboptimal in RA. Patients who were better screened were more frequently already followed-up for hyperlipidemia and were more frequently receiving biologics but more less frequently smokers. Thus it seems getting optimal screening may reflect both patient characteristics but also physician attention to comorbidity in certain situations. Empowering patients to be responsible for the comorbidity screening reminders should be explored.

References:

[1] Ref 1. Baillet A, Gossec L et al. Ann Rheum Dis. 2016;75(6):965-73.

[2] Ref 2. Gossec L et al. Joint Bone Spine. 2016;83(5):501-9.

[3] Ref 3. Dougados M, Soubrier M et al. Ann Rheum Dis. 2015;74(9):1725-33.

[4] Ref 4. Gossec L et al. Arthritis Rheumatol. 2016; 68 (suppl 10): abstract. http://acrabstracts.org/abstract/screening-for-and-managementof-comorbidities-after-a-nurse-led-program-results-of-a-3-year-longitudinalstudy-in-776-established-ra-patients/.

Acknowledgements: grant from Roche France and from the French National Research Program (PHRC AOM 12072).

Disclosure of Interest: None declared

DOI: 10.1136/annrheumdis-2017-eular.2991

\section{THU0153 VASCULAR MORBIMORTALITY IN RHEUMATOID ARTHRITIS (RA) PATIENTS AND ITS RELATION WITH VASCULAR STUDY}

L. Montolio-Chiva, M. Robustillo-Villarino, C. Vergara-Dangond,

M. Aguilar-Zamora, E. Valls-Pascual, D. Ybáñez-García, A. Martínez-Ferrer, V. Núñez-Monje, J.J. Alegre-Sancho. Rheumatology, Hospital Universitario Dr. Peset, Valencia, Spain

Background: RA patients have a higher risk of vascular events, especially cardiac ones. Besides, mortality in these patients is $54 \%$ higher than the general population. Nowadays, we have non-invasive techniques that allow us to detect subclinical vascular damage.

Objectives: To describe subclinical vascular affection in a sample of RA patients and to explore its relationship with mortality and with the development of vascular events.

Methods: Ambispective observational study with analytical components. We included, consecutively, RA patients controlled in a tertiary hospital. We gathered demographic (sex, age, body mass index [BMI]), clinical (traditional vascular risk factors, previous vascular events), and analytical variables (atherogenic index, glomerular filtration [GF] [MDRD], CRP, ESR). Other variables were collected retrospectively from the electronic medical record. We estimated the modified SCORE. We explored the extracranial branches of the carotid artery with an Esaote MyLab70XVG ultrasound device with a linear probe $(7-12 \mathrm{mHz})$ and an automated program measuring intima media thickness (IMT) by radiofrequency ("Quality intima media thickness in real-time, QIMT"), and the presence of atheroma plaques, as per the Mannheim consensus, was registered. We also determined pulse wave velocity (PWV) by a validated MobilOGraph ${ }^{\circledR}$ device. We considered an $I M T>900 \mu$ and a $P W V \geq 10 \mathrm{~m} / \mathrm{s}$ as pathologic values. We prospectively collected mortality and the development of new vascular events over three years. Statistical analysis was performed using SPSS 17.0 software. Results: We included 198 patients, excluding 13 because of previous vascular events. The mean age was 65,8 years (DE 13,3) and most of them were women (76,2\%). The mean BMI was 27,29 (DE 4,84). $27 \%$ were smokers, $42,7 \%$ hypertensive, $46,7 \%$ dyslipemic and $10,8 \%$ were diabetic. The mean duration of RA was 17,37 years. $74,6 \%$ of patients were seropositive (RF and/or ACPA) and $75,5 \%$ had erosions. $74,6 \%$ received glucocorticoids, $58,4 \%$ NSAIDs, $98,9 \%$ DMARDs and $35,7 \%$ biologic therapies. The mean CRP and ESR were $9,45 \mathrm{mg} / \mathrm{L}$ (DE: 32,2$)$ and $14,04 \mathrm{~mm} / \mathrm{h}(\mathrm{DE}: 14,46)$, respectively. The mean modified SCORE was 1,81 (DE: 1,79).

Regarding the vascular study, $48,6 \%$ of the patients had atheroma plaques, $31,7 \%$ had a pathologic PWV with a mean value of 9,13 (DE 2,12), and $16,7 \%$ had a pathologic IMT with a mean value of $754 \mu(\mathrm{DE} 168,52)$.

During 3 years of follow up, we registered $26(14,1 \%)$ vascular events: 9,7\% cardiac, $2,1 \%$ cerebral and 2,2\% peripheral. There were 5 deaths: 3 vascular, 1 infectious and 1 respiratory. The development of vascular events was related with the presence of atheroma plaques $(p 0,008)$ and with pathologic PWV (p 
0,028 ), as well as with the presence of erosions, GF, HTA and dyslipidemia. The appearance of cardiac events was related, also, with the use of NSAID $(p 0,041)$. The presence of a pathologic IMT $(p 0,032)$ and HTA $(p 0,044)$ were the only variables related with death from any cause.

Conclusions: A combination of carotid ultrasonography and arterial stiffness study can help us to best identify patients with RA who have an increased risk of dying or developing a vascular event.

Disclosure of Interest: None declared

DOI: 10.1136/annrheumdis-2017-eular.3469

\section{THU0154 ASSOCIATION BETWEEN PLASMA LIPIDS, DISEASE ACTIVITY AND PCSK9 LEVELS IN RA PATIENTS}

M. Heslinga ${ }^{1}$, G. Lambert ${ }^{2}$, A. Thedrez ${ }^{3}$, J. Kastelein ${ }^{4}$, M. Nurmohamed ${ }^{1,5}$. ${ }^{1}$ Amsterdam Rheumatology and immunology Center / Reade, Amsterdam, Netherlands; ${ }^{2}$ University of la Reúnion, Saint-Denis; ${ }^{3}$ University of Nantes, Nantes, France; ${ }^{4}$ Academic Medical Center $;{ }^{5}$ Amsterdam Rheumatology and Immunology Center / VU University Medical Center, Amsterdam, Netherlands

Background: Patients with rheumatoid arthritis (RA) are at increased cardiovascular risk with contribution of both inflammation and traditional risk factors. Dyslipidemia is an important risk factor and lipid-lowering therapy plays a key role in cardio-preventive treatment. A new class of low density lipoprotein cholesterol (LDL-C) lowering drugs, proprotein convertase subtilisin/kexin type 9 (PCSK9)inhibitors are now emerging. In view of a lower rate of musculoskeletal side effects these drugs might be preferred over statins in patients with RA. Active inflammation in RA leads to a decline in lipid levels, but the relation between inflammation and PCSK9 levels is unknown.

Objectives: To assess PSCK9 levels in RA patients, and the relationship with lipid levels and disease activity.

Methods: PSCK9 levels were assessed using ELISA in 97 randomly selected patients. Lipid profile assessment comprised TC, HDL-C, LDL-C and triglycerides. Disease activity was assessed using disease activity score of 28 joints (DAS28). Results: The mean age of RA patients was 54.5 years $( \pm 10.8)$ and they were predominantly female $(74.2 \%)$. The mean PCSK9 value in RA patients was 214.75 ( \pm 73.3), which is similar to that in the general population [1]. PCSK9 values were associated with TC (corrected B $22.34,95 \% \mathrm{Cl} 6.80-37.88, \mathrm{p} 0.005$ ) and triglycerides (corrected B 21.02, 95\% Cl -0.84-42.89, p0.044) (table 2). 77 patients had low disease activity (DAS28 $\leq 3.2$ ), 11 patients had medium disease activity (DAS28 $>3.2$ and $\leq 5.1$ ) and 20 patients had highly active disease (DAS28 >5.1). Mean PCSK9 values were $213.01,246.96$ and $258.30 \mathrm{ng} / \mathrm{mL}$, respectively. Patients with active disease had a higher PCSK9 level (corrected B $42.55595 \%$ $\mathrm{Cl}$ 0.769-84.341, p 0.046) compared to patients with low disease activity (table 1).

Table 1. Relation between plasma lipids, disease activity and PCSK9 levels

\begin{tabular}{|c|c|c|c|}
\hline & $B$ & $95 \% \mathrm{Cl}$ & P-value \\
\hline $\mathrm{TC}$ & 21.86 & $7.03-36.69$ & 0.004 \\
\hline & 21.88 & $6.52-37.24$ & 0.006 \\
\hline ** & 22.34 & $6.80-37.88$ & 0.005 \\
\hline Triglycerides & 21.02 & $-0.84-42.89$ & 0.059 \\
\hline * & 19.81 & $-2.91-42.53$ & 0.087 \\
\hline ** & 24.81 & $0.68-48.94$ & 0.044 \\
\hline HDL-C & 13.03 & $-14.97-41.03$ & 0.358 \\
\hline & 14.57 & $-14.61-43.79$ & 0.324 \\
\hline ** & 11.04 & $-20.15-42.23$ & 0.484 \\
\hline LDL-C & 14.23 & $-1.93-30.38$ & 0.084 \\
\hline & 13.59 & $-2.81-29.99$ & 0.103 \\
\hline ** & 15.22 & $-1.51-31.95$ & 0.074 \\
\hline $\mathrm{TC} / \mathrm{HDL}$ ratio & 6.28 & $-4.4-16.9$ & 0.245 \\
\hline & 5.95 & $-5.12-17.03$ & 0.289 \\
\hline ** & 8.64 & $-3.36-20.64$ & 0.156 \\
\hline DAS28 (low vs. high disease activity) ${ }^{\dagger}$ & 45.284 & $4.865-85.884$ & 0.029 \\
\hline & 42.028 & $0.652-83.405$ & 0.047 \\
\hline ** & 42.555 & $0.769-84.341$ & 0.046 \\
\hline
\end{tabular}

${ }^{*}$ Corrected for age and gender, ${ }^{* *}$ Corrected for age, gender and BMI. ${ }^{+}$Low disease activity: DAS28 > 3.2, and high disease activity: DAS28 <5.1. BMI = Body Mass Index, DAS28 = Disease activity score of 28 joints, $\mathrm{HDL}=$ high density lipoprotein, $\mathrm{LDL}=$ low density lipoprotein, $\mathrm{TC}=$ Total cholesterol.

Conclusions: PCSK9 levels in RA are similar to the general population. RA patients with active disease had higher PCSK9 levels compared to patients with low disease activity. Altogether, PCSK9 inhibitors could be an alternative treatment for dyslipidemia in RA patients who experience side effects of statins, albeit that a formal trial still has to be conducted in this category of patients.

References:

[1] Lambert G, Petrides F, Chatelais M et al. J Am Coll Cardiol. 2014 Jun 10;63(22):2365-73.

Disclosure of Interest: None declared

DOI: 10.1136/annrheumdis-2017-eular.2121

\section{THU0155 IMPACT OF BASELINE MODIFIED RHEUMATIC DISEASE COMORBIDITY INDEX (MRDCI) ON DRUG SURVIVAL AND EFFECTIVENESS OF BIOLOGICAL DRUGS IN PATIENTS AFFECTED WITH RHEUMATOID ARTHRITIS (RA), SPONDYLOARTHRITIS (SPA), AND PSORIATIC ARTHRITIS (PSA) IN REAL-WORLD SETTINGS}

M. Fornaro ${ }^{1}$, M. Di Carlo ${ }^{2}$, S. Gentileschi ${ }^{3}$, M.G. Giannotta ${ }^{1}$, L. Cantarini ${ }^{3}$, F. Salaffi ${ }^{2}$, G. Lapadula ${ }^{1}$, F. lannone ${ }^{1} .{ }^{1}$ Department of Rheumatology, University of Bari, Bari; ${ }^{2}$ Rheumatology Department, Polytechnic University of Marche, Jesi; ${ }^{3}$ Research Center of Systemic Autoinflammatory Diseases and Behçet's Disease Clinic, Department of Medical Sciences, Surgery and Neurosciences, University of Siena, Siena, Italy

Background: The overall assessment of patients with systemic arthritis can not exclude comorbidities, which may impact therapeutic outcomes.

Objectives: To assess the impact of baseline modified rheumatic disease comorbidity index ${ }^{1}(\mathrm{mRDCl})$ on drug survival and effectiveness of biological drugs in patients affected with Rheumatoid arthritis (RA), Spondyloarthritis (SpA), and Psoriatic Arthritis (PsA) in real-world settings.

Methods: Patients (nr. 635) with RA (nr. 214), SpA (nr. 213), and PsA (nr. 208) starting a biological drug were retrospectively analysed. $\mathrm{mRDCl}$ was scored at baseline, and disease characteristics were recorded at entry and at last observation. Drug retention was analysed using Kaplan-Meier curves. Cox-regression models were used to estimate the association of $\mathrm{mRDCl}$ with drug discontinuation and clinical outcomes, the achievement of clinical remission based on 28 joint-Disease Activity Score (DAS28) $<2.6$ for RA and PsA, and on Ankylosing Spondylitis-C-reactive protein Disease Activity Score (ASDAS-CRP) $<1.3$ for SpA.

Results: Baseline $\mathrm{mRDCl}$ significantly correlated with the number of biological drug switches (rho 0.47). Drug persistence was significantly higher in patients with $\mathrm{mRDCl}=0(96.4 \%)$, than in those with $\mathrm{mRDCl} \geq 2(83.9 \%)$. Compared to $\mathrm{mRDCl} \geq 2$ patients, those without comorbidities showed significantly higher drug survival rate in $\mathrm{PsA}(\mathrm{p}=0.0001)$ or $\mathrm{SpA}(\mathrm{p}=0.02)$, but not in RA (Figure 1). $\mathrm{mRDCl}$ was also found to be a predictor of definitive drug discontinuation (HR 1.53) and of failure to achieve DAS28 based remission in RA (HR 0.66) or PSA (HR 0.77), and ASDAS-CRP driven remission in SpA (HR 0.43).

Table 1. Baseline demographics of patients with Psoriatic Arthritis (PsA), Rheumatoid arthritis (RA), and Spondyloarthritis (SpA)

\begin{tabular}{lcccc}
\hline & All $(\mathrm{n}=635)$ & PsA $(\mathrm{n}=208)$ & $\mathrm{RA}(\mathrm{n}=214)$ & $\mathrm{SpA}(\mathrm{n}=213)$ \\
\hline Age (mean \pm SD) & $51.1 \pm 13$ & $51.3 \pm 12$ & $54.2 \pm 12$ & $47.8 \pm 13$ \\
Female, $\mathrm{n}(\%)$ & $407(64)$ & $136(65)$ & $172(80)$ & $99(46)$ \\
Normal weight (BMI $\leq 25), \mathrm{n}(\%)$ & $278(44)$ & $84(40)$ & $111(52)$ & $83(39)$ \\
Overweight (BMI > 25 $\leq 30), \mathrm{n}(\%)$ & $242(28)$ & $78(37)$ & $64(30)$ & $100(47)$ \\
Obese (BMI >30), $\mathrm{n}(\%)$ & $115(18)$ & $46(22)$ & $39(18)$ & $30(14)$ \\
Disease duration (months) & $79.8 \pm 92$ & $69.9 \pm 123$ & $72.8 \pm 75$ & $74.9 \pm 80$ \\
mRDCl, $\mathrm{n}(\%)$ & & & & \\
0 & $302(48)$ & $87(42)$ & $92(43)$ & $123(58)$ \\
1 & $128(21)$ & $51(25)$ & $44(21)$ & $33(15)$ \\
2 & $88(14)$ & $24(12)$ & $34(16)$ & $30(14)$ \\
3 & $53(8.3)$ & $24(11)$ & $15(7.0)$ & $14(6.6)$ \\
4 & $30(4.7)$ & $12(5.8)$ & $12(5.6)$ & $6(2.8)$ \\
5 & $13(2.0)$ & $5(2.4)$ & $7(3.3)$ & $1(0.5)$ \\
6 & $9(1.4)$ & $2(1.0)$ & $6(2.8)$ & $1(0.5)$ \\
7 & $9(1.4)$ & $2(1.0)$ & $3(1.4)$ & $4(1.9)$ \\
8 & $3(0.5)$ & $1(0.5)$ & $1(0.5)$ & $1(0.5)$ \\
\hline
\end{tabular}

Values are the mean $1 \mathrm{SD}$ unless otherwise indicated. $\mathrm{BMI}=$ Body Mass Index; $\mathrm{mRDCl}=$ modified Rheumatic Diseases Comorbidity Index.
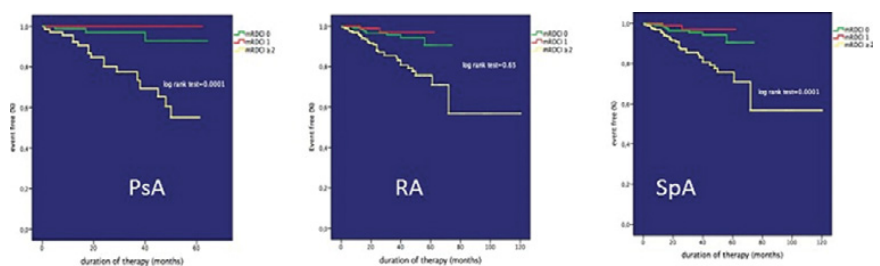

Figure 1. Kaplan-Meier
Psoriatic Arthritis $(\mathrm{P} B \mathrm{~A})$

Conclusions: This study provided evidence that baseline $\mathrm{mRDCl}$ negatively impacts the persistence on biologic treatments and the clinical outcomes in patients with RA, SpA, and PsA in real-life settings.

References:

[1] Staetgens et al. Content and construct validity of the Rheumatic Diseases Comorbidity Index in patients with gout. Rheumatology (2015)Sep;54(9):16591663.

Disclosure of Interest: None declared

DOI: 10.1136/annrheumdis-2017-eular.1502 